\title{
STRATEGY OF EXHIBITING AND PRESENTATION OF ARCHITECTURE AS AN EXHIBITION FORM (with a retrospect of exhibitionary practices in Serbia following 2000)
}

\section{A B S T R A C T}

This paper deals with the existing and possible modalities and strategies of exhibiting and presentation of contemporary architecture in specific exhibition conditions (gallery or museum spaces or in the context of public space), not aiming at perceiving the issue of presentation in all its aspects with regards to the complexity and all the circumstances of this theme expanse. This paper is focused on the level of research of the relations between the real model and its presentation or on the diverse ways of interpretation of the designed model in the context of its possible realization or some of its special program or utopian social function. Also, the focus of the paper is based on the analysis of the media practices of presentation of ideas and concepts in architecture, as well as on the possibility of architecture be presented as professional, artistic and social practice through those media.

In separate part of this paper the practice of exhibition and presentation of the Serbian architecture following 2000 will be presented through analysis of the systems and forms of exhibition in the existing social and cultural conditions of significance for architecture and based on previously provided analyses. 


\section{EXHIBITION AND PRESENTATION OF ARCHITECTURE}

Exhibiting contemporary architecture, its illustrations and plans, has always represented the questionable and often confusing process. Same as in the monumental or monument sculpture it is also in architecture that the perception of its real appearance was almost always an exclusive necessity of its comprehension or aesthetic qualification. Perception of architecture essentially depends on the possibility of experiencing that complex structure in real appearance form.

Comprehended as static form built in situ, presentation of architecture in other space has always presumed a series of specific reasons and methodologies implying also the creation of conditions for the possibility of its real perception. Thus the reasons and ways of exhibiting architecture have mostly eluded the ways and principles of exhibiting photography or art of painting, small format sculptures or other similar and in principle mobile forms the dislocation of which is possible and therefore also the insight into their material and aesthetic appearances and values.

For that reason the primary question of exhibiting architecture has always been: to which extent is its appearance identified with the model of presentation? On the basis of which criteria is this identification established: on the basis of its formal, parameter, program or conceptual contents? In which way are these individual or entire contents demonstrated?

Naturally, therefrom ensues the dilemma in respect to that which happens in the situation when real disproportion between the model and its manifestation is perceived. This circumstance in architecture is of particular significance just for the reason that the purpose in exhibiting and presentation of architecture has mostly, however, not necessarily, been created to explain or refer to the real model.

For those primary, rather simple reasons, exhibiting of architecture was the most logical or most valid in the stage of its design documentation or presupposed concept of architecture and it was so before it has emerged as a realized or built form. The reasons for such exhibiting have their full meaning ranging within the field of presentation of something conceived and which is yet to emerge. Exhibiting of architecture in such procedure depends on the relations of the idea or concept to something non-existent or which is yet to emerge. That way the meaning of the exhibited is identified with the material of the exhibited and even though such structure necessarily directs to its purpose assuming that according to its model or concept a work will be realized, it still remains in the 
domain of self-sufficient and by itself determines the possibility of broadness and quality of its own meaning and determines the ways of interpretation. It is only in the circumstances of exhibiting and perception of the meaning of that which the design or other medium of architecture concept assumes that the entity of possible interpretations and discourses is created and which are based on more or less imaginable narrative components of future realization.

Such relationship of models having the meaning per se and the exclusive intention of providing the future space of interpretation of that assumed by itself is completely contradictory to the presented design or plan which has already been realized as an identified work and that the purpose of that design or plan is to present the real model or indicate to some of interpretative mechanism in interpretation of the meaning of the realized work or only presuppose or propose the possible models of reading that work.

One can presume that the presented architectural plan of the existing architectural work or the presented form of the existing work are interpreted on the level of perception and reading the identicalness and differences between the model and the work, where in the first case it concerns the intention to present the work as it is (to document it, for instance), and in the second case to point out to specific and different aspects of the work which are perceptible by sheer presentation (such as documents, for instance). It is understood that the identicalness of the work and its exhibited presentation is not possible, although it could imply the identical product of interpretation, thus it is equally understood that just within the differences between the work and its presentation in architecture a whole corps of diverse interpretations and cognitions both about the work presentation and about the work itself can be achieved. That is why that within reading this difference a whole series of important interpretative mechanisms can be established and primarily towards comprehension and experiencing architecture as something not necessarily and exclusively related to its own factual (material or form) appearance in space.

The problem of exhibiting architecture has thus fully been framed by possible interpretative mechanism which first of all establish the relationship toward perception of relations: 1) The mode - conceived narrative on the work presented by the model; 2) The model - the work described (presented) by that model; 3) The model - the way of interpretation of the model itself. Within these relations there ranges the necessity of establishing the narratives surpassing the sheer perception of the architectural form and its program contents as the document on the conceived or the existing one. 
The sense of the exhibition presentation of architecture entirely falls within the domain of the implying social and cultural function of architecture and that function of architecture ranges within the immense spectrum of possibilities that with the exhibition presentation it is talked about a great number of diverse aspects which are presented or happen in space, and between the documentary and archiving relation towards architecture as the product of human needs, as far as the function of architecture as an essential cultural and social activity which could be the generator of not only social and cultural changes but also of the ideas and visions by means of which architecture attempts at predicting or starting the most versatile forms of opinion on the world we live in and on the philosophical and cultural views of its future.

The role of exhibition presentation of architecture is therefore necessarily associated with the forms and parameters of social communication which never concern only architecture as item per se (although that is also a possible communication form of architecture) but with significantly broader modalities of cultural and social communication in which architecture is actually only its medium. From this premise the author of this paper will attempt to list and explain different methods of communication in the architecture medium as well as different media by means of which architecture establishes its communication models. This primarily relates to the domain of function and sense of exhibitionary presentation of architecture and the way in which it is communicated with such act in the architecture practice.

Architecture as form is most frequently established or determined by powerful public interests (it is herein thought of architecture in public sector or architecture having certain correspondence with public space or perceptibility in public space) and in that sense exhibiting and presentation of architecture is logical as rather important and often necessary social activity.

Exhibiting architecture in those circumstances makes sense in presenting the social interest or to open up a public debate on public interest or that the social elite on which public space building depends determines or realizes the conditions for its realizations.

Within this frame two extremes of interest presentation through architecture are reflected: from the wishes of an individual or social group to determine the systems of the new or preferred public interest interpretation through architecture medium to the intent that through presentation partial or general interest is promoted out of which the society as whole would realize diverse forms of its benefit through architecture medium. 
Architecture has always and in a most direct way presumed the system of the manner and form of social representation. Hence the very intent of architecture presentation has opened a series of questions which almost always directly concerned the public interest and was more or less carefully articulated by those who supported that interest.

Independent from who was behind the presentation of such public interest in architecture medium, architecture in that function necessarily has the preferred, intended and most frequently accentuated progressivist social communicational component. This component of architecture presentation is always questioning and such its questionability ensues from the reason of multifold ways and forms of its presentation which have their meaning either in particular or partial social interest presented as a general one or through communication systems based on presentation of various types of social and cultural idealities. Also, all these forms of this communication in exhibiting medium of architecture have their purpose of convincing of the benefit of social acting which is articulated by architecture.

These significant positions influence the circumstances from which the necessity develops to articulate mainly accurately determined way and procedure of exhibitionary presentation of architecture. In compliance with the previously presented modalities determining such framework of relationships of the presented and real model actually one perceives not only the possibilities of articulating these different interests but also the ways (modalities) of presenting such interests. It is understood that the ways may take various positions between direct and authentic message proclaimed as public interest to manipulation of the public interest, however, these aspects of communication through intermediary of the displayed models surpass the intended framework of this paper. First of all the intent is to consider the versatile media procedures of exhibiting architecture and in a way that such media are questioned on the elementary level, through relation of difference between the model of presentation and between the conceived or realized form and program of architecture.

One should differentiate between the sheer presentation of architecture as certain formal structure (with a notice that also this form of presentation necessarily stands out from the model reality) and the very way in which that structure is presented. Each form and way of presentation, one or other or some special form, presumes a unique and authentic way of showing or realizing its intent and meaning. 
Most often one encounters the fact that architecture presentation objectively evades the ways and possibilities of its realistic perception (understanding, comprehension and interpretation of architecture in situ). However, that evasion also has its full sense in the idea that with this movement it is made perceptible the actual interest of the one who presents architecture and the set of its formal, aesthetic or ideological criteria or intentions which may or should direct towards the real model.

It often concerns the intent of emphasizing a series of particularities of architecture (a series of details for example, or certain angles of perception or some of its essential functional or conceptual components). And when those particularities more or less emphatically stand out from reality they are the parameter of possible determination or intention in architecture or the sense in architecture.

Very often, for instance, exclusively a detail of certain architectural form is presented as exceptional and the only model of its entire presentation. An interesting wall curtain, structural façade or concrete walls will on the level of its structural credibility speak about the entirety of the architectural form even when that object does not appear as necessary part of presentation. This does not relate only to the circumstance that certain minimalistic architecture form may be presented as true to oneself formal contents through some primary form such as cube or prism, but suggests that within structuring that minimal form there happens indicative visual artness, spatiality or technical and technological structure which is not deprived of broader meanings and that those meanings may be rather diverse, from formal-aesthetic to conceptual or socially active ones.

For instance, a great number of facades which in modern architecture has appeared in the form of text, statements or relief or digital image were possible to present exclusively through presentation of such effects and without that way depriving them of the credibility of that representation which by means of that presentation one has in respect to the object itself. There are examples when such presentations coincide with catalogue presentations of material manufacturers (which, logically, are orientated themselves towards production of excess sense in production and promotion of own artifacts), and also in that case a broader aesthetic or conceptual frame of thus presented architecture can be considered.

An essential difference in respect to presentation and the model is clearly perceived also on the level of the plan. Presenting architecture in representative gallery conditions most often will not relate to the building and contractual 
objects plan but the plan will be presented in its narrower conceptual scope. Not rarely does it happen that such type of plans is prepared subsequently, in the interest of presentation, then when it is necessary to present the structure of intent, idea or concept of architecture in as clear way as possible. This is particularly interesting procedure in which it is post festum re-worked an already produced detailed plan which the future built structure will not essentially deviate from. That is why that exhibited and presented plan does not obligatorily correspond to the real execution/main architectural plan. The corrections of the representation of the real model are subsequently made in order to show more clearly its intended and not necessarily realized sense.

This procedure indicates the logics of pronouncing the model as certain preliminary and conceptual practice which is used also in modalities of exhibiting the art.

Competition designs are most often close to this model of plans presentation with regards to the circumstance that competition solutions mainly stop at the conceptual, preliminary and aesthetic element of architecture. That is why such type of plans actually has also the unique presentation function which, along with the competition conditions, is most often tailored exclusively to the possible forms of exhibiting in order to pass through the system of interpretation and valorization (jury evaluation) and not through necessarily detailed study of all its elements as practiced in the main design.

Within the frame of such of model interpretation it is operated with those architecture contents which are not part of design documentation or main design, for instance. It concerns an attempt with more or less necessity for credibility of presentation to present those elements (such as environmentalism, usability or representativeness) which future architectural structure would produce beyond its formal realization and through its intermediary. It is presumed that also the plan itself or the skill of plan reading may place the observer into the possibility to imagine the mentioned intended qualities of architecture, however, towards the clarity of interpretation or towards an attempt that the observer's attention is introduced into a special interpretation model most often different documentary, textual, visual art, artistic or technical media would be used directed towards forming ambience images which is not possible to present exclusively by formal architecture structure.

It is understandable that the observer's expectations in perception of the model of presentation are most often and often also in necessary correlation with the real model and that to the extent which depends on who and for which 
interests perceives, reads or interprets the model. That is why the aspect of exhibiting and presentation always refers us to the issue of complexity and interdependence of the model and form and meaning of its presentation.

The credibility of that correlation is of primary importance to determine the value of the real model through the presented, providing that is the intent of the one determining the form of presentation, and it need not be necessarily presumed that disproportion in model presentation and the model itself has the sense of error or the attempt of presenting something which is not true, something that does not speak the truth about the model.

It could rather be stated that the perceived disaccord relates to the possibility of providing the orientation of form and ways of exhibiting and presentation according to the intended target group it has been aimed at. A whole series of procedures ensue from this and which will not be herein considered in detail and which concern the form of presentation according to the predefined target group. That target group may be the client or the investor, different professional groups, different social groups or wider public.

On the other hand, the form of exhibiting in the sense of medium according to the specified or non-specified target group may be equally versatile or general and different approaches depend on mutual circumstances of communication between the architects and different target groups and the intentions or requirements in that communication. These circumstances do not enable those who exhibit architecture to necessarily determine the form of communication, however, they always leave the room for them in certain way or medium of communication to set diverse typologies of ways and forms of communication.

Thus the issue of credibility in exhibiting architecture is always resolved in a complex relationship of the one who exhibits and the one who this exhibition is intended for and who interprets that exhibition and, accordingly, in diverse forms by means of which the one exhibiting architecture may manipulate within the expectations of the one who the exhibition and interpretation is intended for.

It rather frequently happens that pointing out by presentation to a certain series of aspects of architecture may alter the perception of that architecture also when that architecture has formally been realized and usable. This would be the most significant model of success of one presentation which concerns the attempt to present the realistic and already existing model. The necessity to perceive architecture integrally, whether as form, function or concept very 
often makes difficult the possibility to perceive delicate elements possessed by it and which may indicate to its particular meaning. Emphasizing these details directs the observer towards new areas of perception which may (but need not) change the observer's awareness of the work.

A completely different circumstance, form or tactics of perception relates to presentation of the future architectural model, the model which is yet to be realized in reality. In that system the credibility of the presented architecture does not have the necessary correlation with future model or that correlation is based on different parameters. It is assumed that such circumstances of presentation are rather based towards conceptual focus of architecture and that they rest more on the sense which they presume per se.

Naturally, a whole series of ways of such contemplation does not remove also other diverse systems of thinking directed towards the conceived and possibly realizable future model.

On the primary professional level the questions will be asked about feasibility, relationship towards the announced context or the influence of the presented model upon that context, towards the very aesthetic, social or ideological significance of the presumed. Hence, these perceptions may be divided into those which contemplate formal and informal aspects of the future model.

The formal aspects of the relationship of the presented and future model attempt to determine the feasibility of the model, for eg., its formally legal conditions for realization, parametric effect of architecture in the context, aesthetic influence upon the context or the very formal aesthetics of the future structure.

On the other hand, the informal aspects of the presented indicate the social and ideological intention of architecture, the sense of its representation or the influence of the aesthetic concept of the future model on the social, political or ideological context.

The most interesting and at the same time the most complex form of architecture presentation relates to the models which are not in the necessary correlation with its own realization.

Those models are most often based on the concept that architecture is primarily important and complex cultural practice the primary task of which is to determine socially preferred forms of space or to be the catalyst of the new comprehension of space. 
The concept of such presentation is based on the attempt to impose a certain space model, to appeal to a social debate on the model of preferred space, to bring about the communication on certain social issues in the architecture and urbanism medium, to present the new aesthetic constructs in architecture, to present architecture as art, etc.

Such models may be rather diverse: utopian, for instance, often without an intention to be realized but more to show professional or cultural interest in correlation with the society, in the form of artistic, textual and other models.

A great number of the existing or historical utopian models has exclusively also counted on its own manifestation quality without an intention beyond that manifestation to presume something more than its interpretation and cultural, social or ideological influence through reading. Thus there exists a great number of architectural works which perform their function in exhibition, gallery or museum systems and that is where they stop. Presentation of utopian works or so-called "paper architecture" in exhibition conditions has the function to establish the parameters of thinking of architecture and the society or to create the visions of the new, cultural, aesthetic and ideological parameters of that new desirable society by means of architecture medium. This condition quality in the history of architecture and culture has often left greater trace than those manifested by real architecture, or was significant at least on that level on which the influence had equally valuable existing manifest forms of architecture which determined the end rules in future and shifted the boundaries of practice thinking.

Utopian architecture is presented as the value within the gallery or museum format equal to the way in which art is presented, and in the equal conditions with its professional textual or bibliographical presentation or other forms of possible readability.

At this point it becomes appropriate to make a digression which relates to the issue of art presentation in conditions when that art is based on the unique and inimitable event. It is first of all thought here of the forms from the domain of expanded media in art which acquire the social identity in modernism and with the emergence of neo avant-garde movements they become equally represented (in the conditions of art exhibiting and presentation) as well as so-called classic art media like painting, sculpture, graphic art and photography.

Especially with standardization of performance or happenings in art the issue of presentation of the unique art event following its realization or duration is 
raised. There the issue of documenting and archiving is raised as a key one: with regards to the art event having been completed, in which ways is it possible to make its subsequent presentation and interpretation? In such circumstances these art practices on the whole deal with the mentioned strategies in which the relationship between the real model and its subsequent presentation is structured.

This necessity of transforming the way of artwork exhibiting and the strategies of that transformation have developed to date setting modalities and criteria also for exhibiting architecture. Thereby it is not thought exclusively of exhibiting (and based on that exhibiting the possible interpretation) of historical events within the field of architecture or historical examples in architecture as much as of the change of paradigm of exhibiting and presentation of architecture. In that sense the architectural practice follows these systems of exhibiting only when it itself becomes some form of performance, happening or specific "situation" as a very important theme in architecture from neo avant-garde to date.

In this context the way of architecture presentation is rather often transformed into presentation of forms of space or architecture perception or into presentation of the events or situations of architecture. It does not only concern an enormous number of modern artworks inspired by a possible "event" of architecture but also a series of rather methodical ways for architecture to present its own work. This methodology of exhibiting ranges within a wide span from the form of noting down and documents of architecture perception in more or less abstract form to creation of complex ambience installations or video works thematizing real or imagined event of architecture.

In that sense the architectural practice has in almost all segments become equal to other art practices and in the course of the last few decades thereby secured for itself a significantly broader cultural and social role.

\section{Exhibiting Media of Architecture}

At the primary medium level it is only just the importance of exhibiting elementary art drawing or painting in architecture which implies in itself a wide range of possible methodologies and their interpretations.

It is understood that a series of exhibited visual art representations of architecture or urbanism in the form of elementary art drawing or painting (sketch or note) may also take the form in a range from recording the seen architecture, historical artifacts of architecture, for example, to complex 
visual art interpretation of architecture in which the process of its structuring, thoughtful flow of its constitution, to preferred ambience values of the assumed architecture in the process of its conceptualization.

On an extremely elementary level we are witnessing common visual representation of architecture through its subsequent artistic interpretation by drawing or image. There is not a small number of ways to exhibit architecture that relates to this elementary process of its presentation. However, the main issue at this level of presentation also relates not as much to credibility of real model representation as much to the attempt to record the difference in the form of impression or expression of the seen.

A banal procedure of presentation would relate to subsequent literal interpretation of the built architecture by the author of that architecture who presents its formal appearance in art medium of drawing or image. Literality of such representation speaks rather about the author's intention to show his/ her art skill than it is the author's intent to suggest the objective art value of architecture. In general, this practice coincides with the same such examples in art destabilized by the advent of technological means of reproduction with the appearance of photography or film.

It is understood, naturally, that very emphasizing of fine arts itself can be a legitimate artistic procedure but in architecture it has principally been multifold simplified by the fact that this procedure leads to overlapping of the relationship of the skill in architecture production in relation to the production skills of its artistic interpretation through the medium of visual art drawing or some related medium used for imitation.

Hence there is a certain difference in representing architecture with no intent to mimic or imitate its realistic appearance but a significant step in an attempt to establish a particular narrative or visual art discourse directing to specific and usually subjective properties of the seen which affect the perception and awareness of the observer in revealing the form and meaning of architecture.

In that sense the exhibited art drawing of architecture may produce a rather wide spectrum of possible interpretations. A whole series of experiences and ways of work perceptions is achieved by visual artness, from emphasizing the important formal components of architecture and accentuating its fundamental formal values to procedures in which architecture is presented as a system of ambience, narrative, conceptual or other experienced values. That visual 
artness of work-pieces (in relation to other work-piece, in this case the work of architecture) has a specific semantic value where it is not about simple reproduction but rather emphasizing the substantial, preferred or culturally and socially interesting or useful.

Besides the possibility that by visual art representation in a variety of media and also in the visual art drawing medium it is indicated to many details of great importance for understanding architecture, such as presentation of its construction, details, specific values that are not necessarily visible, there is a whole set of different narrative discourses, which may be the intention in presentation of architecture and ultimately, in the expansion of the area for its complex interpretation.

One domain of such medium of presentation is of particular importance and relates to the attempt of emphasizing the process of architecture constitution. The process generally involves a complex narrative component that describes the system of meaningful form constitution and proves the ways of objectivity and validity of that constitution. Presentations of already realized architecture almost as per the definition presuppose some of the systems of representing the way in which it, in the design process, has been constituted as a form or content.

Such procedures have been calculated to the attempt of convincing proving that the formation of the architecture occurred in a process that is complex, thoughtful, methodologically sound, and ultimately persuasive and very often, irreplaceable. Although this proving of process indispensability that leads from the sketch to architecture realization has its important components of the document and belongs to the attempt of emphasizing the importance of the documents and records of the process, the meaning of this exhibiting presentation is usually calculated to the influence upon the observer who, in a certain sense, is requested to believe in the necessity of constitution of "just such" or "very specific" real model and validation of the real model by the person who perceives it.

Art drawing of architecture has always confirmed its self-value in forms of presenting the process of architecture constitution rather than in the very form of presenting architecture as an appearance form. A series of free-handmade or digital representations of architecture (which remain preserved as solutions of intermediate phases of the design process) present the designing by-product and may be significant for the identification of narrative of architecture constitution. In that case narration can range from the logical movement from the initial concept to realization of architecture through meaningful procedure 
of design process to presentation of the necessary changes that due to the circumstances of the production process of architecture affect the reshaping of its ideas from the initial to the final form and program content.

Exhibiting these artifacts can be ambiguous and we often witness that a range of appropriateness or sense of their presentation may be more or less valuable towards the perception of real qualities of the existing model.

In the course of this analysis, the certain most radical sense of exhibiting might contain communication facts relevant to architecture constitution. As a design process, it goes through necessary phases of communication at different relations: among the authors, the author and co-workers, the author and the clients or the author and the social structures related to the process of investment and construction. Also, archives as byproducts of this process may comprise various forms of text, documents, contracts, photographs or a variety of media presentations.

The skill of presentation of the idea in the form of sketches presented to the client in the studio, at the building site or at the other place of encounter during the process of creating and producing architecture can be shown as a source of importance for the narrative on the medium of communication between the participants in this process. This process determines literal communicational meaning of the designing process of architecture that an architect may refer to in order to emphasize the general social significance of architecture as a form of communication among various active participants at its own example.

In the so-called participatory architecture the artifacts produced by the involved participants (even when they have no highly specialized professional status but act as nonprofessionals in the production of architecture) may be rather significant artistic or documentary or archival material for exhibiting architecture. This type of presentation can be treated as a very convincing presentation form of a specific participatory process with strong cultural and social message.

An example of photography as a medium of presentation of architecture is the most typical form of presenting its formal manifestation and at the same time shows the extent to which the set of the ways of its presentation is diverse.

Actually, the examples of architecture are the most commonly encountered through the medium of photography in the conditions of global and logically unforeseeable production of architecture. This naturally is not a unique role 
of photography used in many ways in presenting the architecture but for the medium of photography it is characteristic that it most frequently assumes the existing (real) model that is visually interpreted.

Both in photography as well as in drawings the basic modus of relations between its appearance and the model addresses the issue of credibility of presentation or the meaning of the ways photography uses to interpret architecture. Therefore, ways can be assumed that it documents architecture, records its state in history or in time, records the events related to its use and so on; but also the ways it presents architecture by layers, often deliberately transforming its appearance in a particular type of formal or narrative statement. That layering which depends on the intention of the person presenting architecture can range from creating from a specific spatial point of view of architecture, the type of lens used and which more or less authentically shows the possibilities of really visible, the transformations of the seen to fully abstracted scenes of the seen in which the medium of photography is used exclusively in order to describe some form of architectural meaning beyond its formally visible.

In one of the possible functions of photography medium it is used as material for creating some kind of photo-collage where there is no interest in representing architecture than to use that specific medium for the purpose of its shaping as a possible way of designing process. At this point photography does no longer imply a relationship with real model and that principle proves that it is not necessarily the system of representation of the seen.

An example of the use of media as a reinterpretation of the seen can be an idea of presenting the space of architecture through documenting its functionality or usability in a way that, from the existing photo material, a precise narrative that suggests the uniqueness and authenticity of its functions which do not necessarily correspond to the real architectural event and its real usefulness is carefully chosen. This refers to the author's intent to speak about the preferred terms of using architecture, its possible systems of use, or ultimately, about the desirable social conditions of usability that represented architecture may involve.

In the recent years we have witnessed the marked use of the digital and also the analogue photography in order to present architecture as a specific ambience or space situation or space event in such a way that these forms very often do not thematize (nor have the intention of thematizing) the very architectural or urban space as much as they tend towards specific and autonomous ambience which is an essential assumption of architecture and not its objectification even 
in the environmental sense. These photographic environmental presentations, often blurred and with occasional post-futuristic representations of movement and rate that describe the event in an abstract space, were created with the idea that the architectural space itself should possess the same kind of effect on the observer or to provide it by its formal structure.

In not so small number of examples of modern interpretations of architecture with the medium of photography (as well as the other media that shall be discussed later) of great importance are those examples which place in correlation architecture itself and artifacts surrounding it or serving as its usable or component part. Typology of these artifacts are virtually endless and are based on a specific symbology or signification that produce imputed artifacts in architecture, like a zeppelin, aircraft or automobile (as technical and technological means of great importance for the progressivist modernism campaign) to setting relations of specific modern forms of cultural (often fashion or design) models of human behavior in space of architecture or in relation of that behavior towards represented model of architecture.

In this case it is always about an attempt of locating or presenting architecture in the preferred social or cultural context. Although the context is not necessarily achievable, the intention of exhibiting or presentation of architecture in the system tends to describe the author's idea about the selfintent, to generate by the specific form of the relation between architecture and artifacts following it, special cultural or social model of living in the context of the proposed architecture or to locate architecture by interpretation in that social or cultural specificity which is usually a progressivist, sometimes futuristic or utopian.

Same as the relation of presented portrait or figure or group of figures in the context of architecture has the intention to describe the ways of usability of space it is equally important the choice of a specific cultural or social models of these appearances in order to provide special cultural or social meaning to architecture itself. This process goes from banal intentions of building some usable architectural representation to complex imputations of artifacts that are in the service of progressivist, futuristic or utopian ideas in architecture which the cultural complexity of the added artifacts defines its broadened meaning for.

This important circumstance of setting relations of architecture representation and the added existing and imagined cultural artifacts that are not in the described relation with the formal form of architecture but describe 
its broadened meaning, naturally, concerns all modalities and media of presentation and exhibiting of architecture, thus there will be no discussion on it further on with an idea that such type of possible relation among elements of media is presumed.

Naturally, it is another question in what sense this type of setting relations is performed in the ways of exhibiting architecture at the level of relationship of the formal or aesthetic components of architecture and pertaining artifacts values calculated to raise awareness of percipients on credibility of architecture. It is assumed that this consent is not always in the necessary connection and it is often just an expression of a wish of the person presenting architecture to upgrade its intended meaning. At this point it is often revealed the weakness of the active participants in presentation that formal and upgraded sense of architecture is often affirmed in a unique cultural model of architecture which is the presentation intention. But, this inconsistent form of presentation may also suggest a range of meanings in architecture from the true intention of the author to send out a specific message to the intent that on the basis of different models of interpretation based on perceiving the differences within the exhibited part confirm the possible designed systems of specific interpretation.

The architectural model certainly represents the most convincing possible form of presenting architecture primarily due to the circumstances that with such medium architecture can be presented (interpreted) literally but in a reduced form and in different proportions of reduction that according to that proportion may have different levels of presentation details. Essentially, however, the model does not imitate reality of the conceived or existing model of architecture in necessarily literal way but also the form of model presentation itself implies the relation toward the author's intentions in terms of describing formal, program or conceptual characteristics of the design or the realized works of architecture.

The literality of the reduced presentation through the medium of the model produces accurate insight into all formal characteristics of the work. The program concept of the model, however, may occupy the range between emphasizing the important shaping characteristics (where it usually comes to simplifying of form characteristics of the work) and the way to present the process of form analyzing and establishing conditions for its necessary formation in context by variety of shaping methods. The possibility to arrive at the conclusions on the preferred form of architecture through the process of modeling does not exclude the possibility that these sections are used as 
descriptions of the necessity of certain constitutional forms of architecture program. Therefore, exhibiting architecture is often presented in the form of representing a variety of section states of the modeled form with the usual closing presentations of what is planned for the production of architecture or that which describes and documents methods of work creation.

It is presumed that one type of literal and detailed presentations of architecture through its reduced model in the most authentic way affects the perception of the real (existing) form. This illustration mechanism which in an almost spiritual way introduces the observer has its objective limitations which specifically relate to the inability of insight into more complex program and environmental characteristics of the work because the model perception itself is mostly confined to the formal aspects of architecture.

It is common practice, however, that from the framework of this methodology of designing through model, the works are crystallized with no essential intent to illustrate reality but to form the process of model building as a form of production possessing the characteristics of sculptural orientation. Such act often suggests actually essential environmental, conceptual or program characteristics of the work whereby the meaningfulness of architecture is emphasized not only and exclusively in its formal shape. Exhibiting these types of artifacts may run in the area from presentation of the process of architecture constitution to a completely conceptual sculptural works whose presentation intention comes within the domain of artistic interpretation of form.

Also, the possibility of manipulation with various types of materials within the model medium which need not necessarily suit real intentions in realization of architecture may suggest certain program and conceptual definition of architecture just as with incorporating specific previously discussed artifacts (such as figures, vehicles, advertising, etc.) in the context of the model.

In the ultimate consequence of this media of architecture presentation there emerge the forms in which proportion of model in a gallery or museum conditions reaches its objective proportions and becomes some kind of transposition of the reality of architecture in the space of presentation. It is understood that the gesture could be an imitation of reality or objective representation of the existing work or the work that existed.

This certainly is not about an attempt to create a specific ambience within the exhibition space or architectural intervention in the exhibition space but this kind of work has been calculated to the intention of model transposition in 
the exhibition space and the ability to create circumstances of documenting architecture in which the observer is brought into state of complete recognition of the circumstances of the imitated space.

An already hinted possibility of creating completely realistic presentation of architecture through model has its special meaning in the use of modern digital technologies. With the advent of modern (digital) presentation media, which became the standard medium for general use in the early 1990s, the possibility of a precise definition of the projected model has been accomplished. There is no doubt that this type of emphasizing the identity of the model and its future realization has a special meaning in producing architecture in whose process this kind of clearness is usually necessary. Computer models (especially digitally generated 3D models) have become a binding manner of addressing in architecture when it is aimed at credible relation of the representation and that which will exist as an objective reality of built architecture.

What is significantly more interesting concerning this text refers to the difference or designing potential which can establish the exhibiting architecture in this medium towards reality or the future of architecture.

In the most important sense, the $3 \mathrm{D}$ digital models equally convincingly are not only the forms of designer and contractor intentions in architecture and urbanism but they also achieve a great opportunity of ideas and visions in architecture that are not necessarily planned for the realization but represent some kind of program or utopian representation in architecture. This procedure is calculated to the idea that every professional, cultural or social purpose may in the form of credible realistic representation be objectively imputed into reality. In that sense, that kind of model representation has a very powerful social message just because it objectively demonstrates formal but not necessarily objective conditionality of realization.

Only the form of digital motion image or motion animation of architecture that is enabled by the conditions of the $3 \mathrm{D}$ digital presentation will be mentioned here. With all the effectiveness of this kind of exhibiting architecture the assumption is that this form, in all its meanings, coincides with the expressions of $3 \mathrm{D}$ digital model. It is understood that by this form of presentation the effectiveness of the experience of architecture is increased in which as in the film it may be suggested a process of moving through space. In a rather significant form this kind of animation does not tend to complete imitation of movement through architecture as much as it describes various processes of 
its constitution, usability, parametric structure, ambience and the like. On the very complex level animation can present the manifest of the program of future architecture or some form of credible utopia representations with an engaged social message.

Levels of presentation are implied to be varied and derived according to the intentions of addressing in architectural presentation to the relationship towards the requests for insights of the interest groups in relation to their needs in the field of architecture and its eventually envisaged realization. In these circumstances too, the levels of presentation by this medium do need not necessarily reach exclusively for objective representations of the built or designed structure as much as to the modalities within the credibility of the ways in which architecture should accomplish its communicational and meaningful potential. Accordingly, digital modeling frequently remains in the range from primary representational forms to complex diagrammatic structures directed towards different parameters of its functional, substantive or program structure.

On the radical level of media use the 3D digital models are presented as program schemes and representation of architecture where the formal structure of representation does not in any way correspond to the objective formal or even functional aspect of architecture but emphasizes its conceptual, parametric, programming or intended applicable aspect in the form of a diagram. Among other things, presentation of diagram in architecture is intended to indicate to the elements of the strategy of shaping process and confirm the validity of its program constitution.

It is quite evident that these forms of presentation are not an exclusive privilege of digital media, but in that sense it is important to emphasize the fact that digital media of communication naturally have the potential that exceeds the persuasiveness of the presentation and enter a complex discourse of actualization of the means of communication through the contents of the modern media.

The innovation of exhibiting and presentation medium itself necessarily establishes a special kind of potential in social communication. It logically decreases with time of its usage and with the circumstances of its own standardization in social communication, but the fact cannot be overlooked that the choice alone of this type of media presentation naturally has its own specific cultural and social reflection. That reflection is most often related to the potential of the media to convincingly confirm their technological progressivist component even when its objective meaning can be confirmed by other means. 
This fact that the type and selection of technological medium in presentation necessarily add a certain kind of meaning to the presented and very often and quite independently from the significance and meaning of the presented, often determine the specific intention of the person wishing to communicate in the field of architecture through its presentation.

The model of appreciation of modern media representation has usually been calculated not only to the idea that in modern conditions of life it should be communicated with modern means of expression, but also to the idea that new communication media such as digital forms, the Internet or the environments or various forms of social networks hold a wide range of more or less desirable progressivist ideas in communication.

The selection of media alone can always present some clear social message. Thus, for example, the use of conventional drawing medium, in addition to meaning and communication potential of the presented, necessarily presupposes either intention to point out the meaningfulness of the traditional form of expression or to suggest the fact that there are equal opportunities for expression independent from media form of that expression. Often this choice of media is an undeniable message of protest against the form or meaning of some form of media mostly against the new, widespread and conditionally toofast standardized media.

The whole spectrum of ways of addressing by new or modern technological communication media has had different modalities of functioning in exhibiting and presentation of architecture, ranging from the ability to present more effectively the complementarity of architecture and the new media on the level of imputation in presenting architecture of modern forms of communication; from the new forms of technical means (the topic of computers, billboards or on-screen images in architecture) to the attempt to present whole concept of architecture as a unique digital structure which behavior and functioning imitate processes and procedures of the digital computer media. Exhibiting architecture in these circumstances means representation of architecture as software of a new digital medium, which can have more or less variable formal structure in accordance with the procedures of the digital software.

It is understood that in a powerful social message the use of new media there comes to importance also the circumstance to filtrate traditional or classic forms of expression such as drawing, painting, sculpture and photography through modern means of expression. An interesting fact is that with this process an 
attempt is often made to express the belief of complementarity or equal value of different media, both traditional and modern, and that on the other hand, these media are either put into function of new ways of communication or, in a relatively primitive way, to insist exclusively on the power to use new technical means in presentation of traditional forms of expression without the intent of adapting the very form of presentation to the new forms and meanings in communication.

At the significant level of this analysis of the media of exhibiting architecture, there are media that are structurally complementary to architecture. This complementarity results from the relation of architectural practice as practice of space shaping with multi-layer media presentation in space and it is done in such a way that the medium of architecture as a medium of articulation of space sets authentic ways of the own spatial realization of space.

At the elementary level architecture is presented as kind of assemblage as an exhibition work composed of diverse elements that are visually or conceptually assembled into a spatial entity. The elements of such space setting may be medium identical, like an attempt while using different types or sizes photographs, for example, in mutual spatial relation to establish an impression about the entity of some architectural work or vision, to the practice that assemblage is made of diverse materialized forms or media representations by means of which the meaningful entity is formed into an unique spatial event. The situation where by means of assemblage the documents, materials, drawings, plans or video recordings are rendered into relation creates an impression of complexity of architectural work and the effect on its overall experiencing not only as realized or imagined form of architecture but as an architecture of complex operative, creative and experiential process.

In the form of installation architecture achieves its full formal credibility because by means of the technical elements of presentation architecture becomes an autonomous spatial form within the gallery or exhibition space. This space can often be a public urban space where architectural work becomes temporary architectonic spatial structure in the form of installation.

The model of exhibiting in the form of installation usually, but not necessarily, creates specific ambience in the exhibiting space and in that respect it nears the situation or the event of the architectural space itself. Its meaning or message, however, may be understood in very different ways. At the elementary level, the architect or the exhibitor handle one type of procedure in which a gallery or exhibition space becomes a space of architectural intervention on the very spot. 
In not so small number of examples, that space becomes a place of temporary architecture construction or peculiar architectonic, more or less abstracted assemblies. Within the space architectural structure can be built according to the particular realistic model from practice. With this procedure an attempt is made to present the existing model of architecture by installation in the most convincing way. The difference between such installation and the model always relates to the circumstance that with the model the proportion and material of which is presented are varied and in the case of installation literal copying of existing model in more or less identical or similar spatial assemblies is done. Thereby the installation becomes a possible realistic part (detail) or the entity of the existing model.

On the other hand the installation in space can be made by entering some realistic architectural form in space, in a manner of its transfer into exhibiting context, the possibility of disassembling and dislocating a certain architectural structure into exhibiting space and so on.

This practice of construction as per the real model is usually related to the classical forms of museum exhibiting of architectural space where more or less traditional or modern models are installed in the space with an intention of displaying the real model of architecture in the actual, environmental, educational or other way. That construction can be followed by a series of engineering technological devices which combine the built structure, for example, by broadcasting an authentic sound or music, by documentary screen image or by the possibilities of sensitizing the senses of touch and the like, resulting in a higher level of exhibits credibility.

In certain cases complete decomposition or deconstruction of real model can be performed in the attempt that by means of presentation it is pointed out to specific conceptual and narrative components of the existing architecture in which the installation usually has the function of presenting certain cultural or social aspects of urban life or life in architecture.

This type of installation constituted as a relation to the real model is not exclusive, nor even the most common exhibiting architecture model in the form of installation. It is commonly conceived as a form whose purpose is to form a new type of space whose suggestiveness has diverse intentions, from ambience to the conceptual (textual or abstract, for example).

Ambience installations are trying to realize a new type of space by means of which gests exactly determined or complex kind of space experience is 
suggested. Ambience installation may include material (physical or technical) spatial elements that create new (abstract, for example) spatial forms with suggestiveness affecting the experience of the observer but also the structures that are program and aiming at determination of aspects of possible or utopian future with an idea of achieving new experience of space. This type of installation can be calculated to the intention that within the existing usable space characteristic a new form of its usability or experience in ambience medium is established or that ambience is presumed as an entirely new idea of experience of space that can be focused on the bases of redefinition of existing space or new program practice or utopian vision of space.

Ambience form is not produced solely with an intention of experiencing the ambience by such formal elements of the installation as much that these elements, in accordance with different ways of observers sensitizing, affect his/her awareness and experience of space. Therefore, a variety of technical tools which sensitize different senses of percipients are the most commonly used and combined for this type of installation. In respect to the intent and concept of exhibitor different effects or combinations of effects are used by using different technological tools used to produce a specific form of sound, light, smell, tactile materials in space to effects produced by smoke-machines, interactive computer programs and the like.

There is one specific form of ambience and it refers to the various narratives in the medium of isolated space given to the use of the percipient where a special type of stimulus is applied on the person experiencing that space. These isolated ambiences are often some built structures (such as capsules, for example) and are independent from the exhibiting space itself and may be located in different and even public spaces in which they are used as isolated ambience situations simultaneously independent of the environment or designed to achieve special environmental and experiential situation in the environment.

Various effects of the ambience upon the observers are usually examined through these forms; the observer is assured of the possibilities of new (previously non-existing) form of spatial experience, or they are used to affect to change in awareness of desirable ambience spaces such as are envisaged in the future or such forms are established as some projections of certain utopian form of the future.

Interactivity of exhibition installation or interactivity of other presentational forms (which is conditioned by the role of exhibiting itself in the form of various communicational relations of works and the observer and it relates to 
all historical exhibiting forms) has won particularly important place in modern times. The reasons for such kind of actualization of interactive communicational models should be sought in modern social, political and cultural awareness that envisages and often includes the necessity of complete involvement of the observer, not only in the perception of the architectural work or narrative but also in the very process of generating the meaning of the presented work. This social and cultural form of presentation that has become a necessity in modern conditions of exhibiting architecture has acquired the exhibiting forms in which the necessary product of exhibition is a reaction of the observer, his/ her interaction or effect on the functioning of the exhibition.

Exhibiting architecture under these conditions becomes a service of active participants assuming that the final product of exhibiting will actually be the only visible and significant result of the process. That process has the purpose to enable a visible production of meaning fulfilling the sense of exhibiting. In this form of presentation the architect appears as an active participant generating the procedures and media of interactions with no idea of the results that interaction would necessarily produce.

On a historical level of reading media of architecture and art this activity is recognized as a medium of happenings, as an event that does not prejudice its own consequences and reactions but finally operates with the occurred consequences and articulates them in the documents or interprets the findings resulting from the process.

The basic level of the process of interaction of exhibits and percipients establishes formal ways for percipient to use researching means of exhibits using them in the form of archived material, using medium of library or catalogues or using a computer or internet search forms. In the broader sense, with the very setting, he/she can be expected to provide the presentation of the reaction results in the form of text or other types of interventions (additions to the exhibition set, for example) or some other type of specific activities in the exhibiting space.

The modernist concept of presenting ideas in architecture is avoided by these procedures and the tendency is towards communication modalities within the exhibition, weather at the level of communication in exhibition process between those who define actions and behavior of percipients and the percipients themselves, or at the level of open and free communication and literal percipients' participation in realization of the exhibition event. 
At this point it should also be mentioned the fact that the circumstance of interaction of the author and percipient can be based on assumptions that determine communication and interaction as exclusive event level of architecture presentation. The exhibition of architecture is carried out primarily as an event of conversation, conference, round table and workshop with more or less represented media of presentation and primarily presenting examples in the function of the particular way of communication.

That elementary level of communication about issues of importance within architecture and urbanism is profiled by authors of the events, by designing themes and procedures and products of communication. There the authors of the exhibition are placed as mediators of the event with the idea of its more or less achievable result, which could be a book, recording of an interview/ conversation, a directed film or documentary material or other forms of product such as can be produced within operational processes implemented in the workshops.

Most often it happens that in the exhibition circumstances this form of exhibiting usually has an accompanying function in relation to a fixed exhibited (demonstrational) material, however, this is not a necessity of this kind of event. The event can be deprived of any artifacts and supported solely on the process of interaction between the author and the participants.

Thereby the act of exhibiting architecture itself is reduced to opening the possibilities of communication of various stakeholders in architecture on the public plan and by this procedure strong communicational and social role of architecture is emphasized.

All these listed examples of presenting architecture in the exhibition space speak about the possibility that even in the most elementary form of presentation such as a sketch or drawing the widest possible range of narrative in architecture can be shown. Because multilayered media presentation of architecture has its own communicational significance and meaning thus that significance and meaning should be sought beyond the possibility of elaboration of the elementary forms such as plain but often sufficient artistic (drawing, for example) representations of architecture.

The analysis has demonstrated the conditions describing for which communicational reasons, in fact, it is departed from the elementary ways of presenting architecture towards the methods that are more complex and 
multimedia or for which reason the author's concept of exhibiting move towards the reasons and intentions for using only particular media that for those same reasons and intentions more adequate to represent architecture.

\section{Architecture as Art and Art as Architecture in the Exhibiting Space}

It can be said that the most delicate form of exhibiting and presentation of architecture is the ability to guide the architectural thought by specific conceptual strategies of dealing with certain general, professional and theoretical issues that are, as practice, placed before it. There architecture begins to represent a certain "situationist" practice where it responds to given social discourses or other circumstance or creates them itself within a given context transforming it to a newly created "situation". The difference between this and utopian models of promotion is not particularly great but the circumstance should be noted that this contextual approach in the circumstances of modern discourses is less governed by certain visions of the future as much as by the attempt to discuss in situ the social circumstances in the medium of architecture or solve the problems of those, mainly given, circumstances of space.

This practice of communication through the medium of exhibiting and presentations of architecture has gained in importance in the recent decades although such model was practiced almost throughout the entire last century. Extreme complexity of this model occurs in the modern concepts, in the conditions when in the new social circumstances a stronger social and political as well as public interest has emerged supporting the idea of architecture and arts having greater and more direct role in society. The institutions of culture have turned towards models in which the relationship of the society, culture and politics with the models of art and architecture is thematically reexamined on the level of direct communication and with a strong media concept.

Among other things, it has been attempted to finalize the entire history of criticism of museum and gallery practices during the $20^{\text {th }}$ century by new museum and curatorial practices which would be more socially engaged and have more direct influence on social circumstances. In this concept there came to greater influence of curators and museum administrators in direction of opening of galleries and museums to current social and cultural issues and thus the most important form of this practice has become a strong social action instead of inheriting cultural and historical values. 
In this context, exhibiting and presentation of architecture have become a practice of intensified social action. Hence, the fundamental question for architects and curators has become a matter of choosing the topics that will be socially interesting and active and which professional architects and artists together with curators would know how to determine, problematize and articulate.

A great number of topics of immediate social importance have influenced the fact that the architects began being engaged with the mentioned topics in a direct and rather exclusively theoretical or artistic than a specific designing or constructing way.

Following that trail architectural practice has bonded with professional artistic practices in the most direct way. The influence of the architects in the art was continuously growing in the past decades so that up to date it would be almost uninteresting whether art was produced by the educated architects or professional artists. It is understood that this circumstance does not apply only to the influence of the architects on art but also on other social practices and it is clear that in this context architectural profession has a great influence in the world.

For this paper the most crucial significance is the circumstance that the artifacts of architectural presentation and exhibitions have become formal gallery and museum exhibits in various media such as performances, installations, images, photographs or videos. Practically, today there is no medium within which there is no possibility of presenting architecture and in respect to the topics that are not necessarily professional but rather social, cultural or ideological and as such they are necessarily related to the medium or a discourse of architecture or in some way directing or articulating it.

Architectural and artistic practices have met in a particularly visible way at the moment when the form of contextual acting, especially in postmodernism, in an expressed way dealt with possible formal and narrative action "in situ", by work or action or producing specific situations in context. Postmodern practice mostly perceived this contextual action as the way of setting the relationship or "counter placing" of work and its environment as opposites to the idea of autonomous artistic or architectural form in context. From the idea of harmonization process of form with environment to a radical critique of environment by imputation of some contrary formal, narrative or substantial process, this type of intervention has survived as far as contemporary examples as a significant indicator of interests of mentioned practices so they can act in different ways in the production of various relations to the environment. 
Of an interest is the fact that this process in formal and program sense is closer to architecture than to visual art practices as it is generally carried out within given framework of space and in relation to a numerous requirements derived from widely understood notion of environment. Hence the art practices in the recent decades were more sharply observing the process of constituting architecture noting significant capacities for broader social (contextual) action of art in this process.

However, within architecture itself of this in situ activity did not relate only to the question of architectural design and construction, to the issues of specific use of architectural medium in environment but also to a series of practices which, conditionally speaking, in the language of art, dealt with space issues through various media practices such as sculpture, but also installations, multimedia interventions in space and the like.

On a radical level and of a great interest for the paper, architecture becomes a practice of particular actions within a gallery or museum space trying within the given exhibiting space to act in the language of architecture in order to carry out the transformation of space into a special architectural ambience or other media program that in some way throughout the $20^{\text {th }}$ century was almost the exclusive domain of the visual arts.

It is understood that the practices mentioned in this paper do not relate to the role of architecture in constituting exhibition spaces, exhibition installations or in building up specific museum narratives and presentational concepts in which professional architectural understanding of space is mainly necessary, although not also obligatory, nor it so the theme of this paper. However, the action of the architects in gallery space in direction of architecture presentation logically starts form the presumption of space transformation in the context of exhibition or presentational narrative.

Numerous examples in art adopt the logic of typically architectural intervention, most often passing through equally typical architectural process of space designing, in order to realize the ambience, installation or some higher multimedia concept in transformation of the exhibition space. In this sense in the art production there happen the authentic architectural concept of space shaping and at that place one cannot speak any longer about the "specialist" practice of the artist or architect.

At that place the strategies of exhibiting architecture and visual arts or even art in general become identical. 


\section{Conclusion of the First Part of the Paper}

The conclusion of this part of the paper ensues from the fact that the way of exhibiting and presentation of architecture moves in the space between the attempt that it is realistically represented in its form, via the way that its formal content is transformed as far as the conceived and preferred form of the message it should convey, to the way that it, as a conceived form and content, generates a special sense at the level of the specified form of communication.

In all media in which architecture is represented it is visible that each of those media may imply all the (most general) ways to represent architecture in its formal, conceptual, program or content forms. Hence the sense and form of exhibition presentation of architecture does not ensue that much from the medium of its presentation as much form the way in which the medium is used as the holder of the narrative of that which is the aim of communication.

In certain circumstances and depending on the intentions of presentation active participants there are significant reasons to use a certain medium of presentation as valid or necessary one. The selection of such medium will depend primarily on the belief that certain medium provides a special effect on perception and interpretation of the seen. Contemporary circumstances of exhibiting architecture, however, say how the communication medium is not a necessary condition of presentation of its meaning but that it can direct its meaning by certain strategies.

It is most likely that the circumstance of media complementarity will be valid until the moment some other medium has proved to be the medium of some particularly important aspect of architecture and it is probable that such medium will comprise some specificity in perception of that what architecture could be in the future.

\section{EXHIBITIONARY ARCHITECTURE PRACTICES IN SERBIA FOLLOWING 2000}

There is no doubt that relatively narrowed architecture market and large disproportion in regional representation of modern architecture in Serbia, especially since the beginning of the 1990s, places the problem of exhibiting architecture within a set of legalities and that those circumstances make difficult the conditions for architecture to be exhibited and presented with full force and by all means which would be necessary if architecture is understood not only as engineering and building practice but also as an important cultural and social practice of general interest. 
Besides, it is quite noticeable that following 2000 the modalities of exhibiting and presentation of architecture have significantly developed and that such modalities are paid greater social attention to. The reasons for this change are numerous. They primarily start with the circumstances that the very opening of the country towards western-capitalist models of production and social organization are translated also to the domain of culture and art and thereby also to architecture as practice. This does not mean that cultural connections within the field of architecture were not represented even earlier, on the contrary, but it is clearly noticed that the circumstance that systemic social changes enable the new modalities of acting such as are characteristic primarily (although not exclusively) for the western societies, that there is a clear awareness of the professionals about these modalities and that there are evident and dominant intentions to adopt these modalities.

It is assumed that the severity of the social transition slows down the process of changes, additionally made more difficult by permanent social and economic crisis and that in such conditions there is a many-years' long delay in the development of architecture practices, however, it is noticeable that there are significant efforts made to change such circumstances. The change of modalities has been facilitated by modern forms of communication which literally make the instant transmission of information possible from within all fields, and also from the field of architecture, but it is obvious that narrowed social possibilities, first of all in the production of architecture, make difficult the possibility of its exhibiting and presentation in greater and more credible scope.

It is quite another issue why one society is necessarily oriented towards foreign modalities in this thematic field and does not develop its own authentic modalities, however, it is not difficult to come to the conclusion that globalization process, as well as transfer of technology and knowledge, brings along the general characteristics of use of media and technological and economic supports to this media and that these modalities have been universally accepted forms of expression in architecture. It is only beyond these general media standards, and at the level of narrative and concepts in architecture, that authentic local fields of action and communication can be devised. Specific social circumstances have not yet become important and visible field of action within the field of architecture and its exhibiting.

Conventional architecture naturally follows and adopts general standards of action in architecture and the scientific and professional public have not been sufficiently oriented towards the issues whereby architecture is more significantly positioned as an important cultural and social practice in the 
local conditions attempting to become more engaged in the specific and authentic social issues which could lead to identifiability of the local models in architecture and thus in its presentation.

On the other hand, following the developed global standards in the local community turns out to be not only as an important market or economic strategy but also as an important ideological and political model characteristic for the more developed social systems. Thus also the culture of the local community is subjected primarily to the desire of achieving those standards.

Hence the issue of modalities in exhibiting architecture in Serbia is always and primary the issue of achieving the media and conceptual standards and from those circumstance the consequences are drawn for interpretation of these modalities, which rather happens on the level of interpretation of the exhibiting form than on the level of interpretation of the exhibiting content. This is particularly comprehensive in the circumstances when architecture itself, its content and concept, is practically narrowed down to such primary intention.

In the first part of the paper, first of all, the possible strategies of exhibiting architecture have been described with a focus on the relationship of the exhibited (presented) model of architecture as representation or interpretation of the existing model, or at the level of the relationship of that exhibited and presented model according to the conceived form of whether envisaged future realization or utopian conception of the certain communicative socially active model.

The circumstance of the narrowed market of architecture and thus also of its social location has always challenged the form and validity of exhibiting architecture in Serbia casting into doubt the importance that those, mostly universally visible models, are presented.

For that reason the system of presenting architectural production has always relied on recording (practical lists of important realizations or magazine reviews) of those realizations by means of which the expanse of the social field of architecture production was affirmed, rather than it has been attempted to thematize the essential aspects of its constitution by the architecture exhibitions themselves and that these aspects in exhibition conditions be clearly identifiable. It is one question in which way this type of architecture exhibition was subsequently interpreted, very often with clearly perceived qualities and failures of realization, and it is quite another one in which way the very presentation in exhibition conditions implied also clearly expressed and visible strategy of communication and enabled a clear act of interpretation thematizing the integrity of the problem in architecture in a certain period. 
This magazine model of exhibiting most often comprised documenting of the narrowed aspects of architecture through photography, plan or shorter text with an intention to present rather the vast number of themes in architecture than the integral sense of the exhibition which could determine the boundaries of the interpretation model or thematize certain problems in architecture or social issues that are refracted in the medium of architecture and urbanism. Within such narrowed framework of rather versatile (both in formal and also in aesthetic and conceptual sense) individual images and besides major or minor influences of the professional juries and curators to determine the framework and theme of exhibition, it was most frequently that circumstances of overly diverse thematizations and narratives were created in which the architecture exhibition, beyond its formal and usually standardized setting, did not make it possible, based on it, that more complex cultural and social issues of architecture were contemplated except that at the phenomenal level the problematic of production was ascertained and the ability, professionalism and power of the stakeholders within the field of architecture was determined with regards to realizing remarkable public results. Hence this magazine type of exhibition was primarily the indicator of the society power to produce architecture and its meaning.

In a different manner, after 2000 a series of manifestations of architecture in Serbia were formed which did not function as per the magazine model of presentation but tried to problematize wider aspects of cultural and social role of architecture. This was not realized as much on the new medium practices of exhibiting architecture as much as in the attempt to install manifestations as a series of diverse contents, often thematically oriented, in which the event content was oriented towards specific narrative and communication aspects in the form of architectural medium.

It mainly concerned the series of various events in which architecture was presented, interpreted, or based on architecture it was communicated in accordance with the presented models or it was produced in the system of short-lasting workshops usually oriented towards carefully selected and defined thematic of the entire manifestation.

This form of events or manifestations makes use of versatile medium effects of presentation which are often limited by the possibilities of technical and economic realization and so the credibility of these manifestations is rather identified in the effects of introduction, communication or interaction of the active participants than in the real exhibitionary and indicative results. 
A number of manifestations of architecture surpasses the frame of exhibiting architecture and exclusively deals with communication within its various discourses. In that context it does not concern as much the type of the prepared conference exposition and discussion as much the open platforms which do not prejudice presentation of pre-given solutions of presentation as much as they act upon creation of unexpected results and conclusions within the assigned or oriented themes and concepts.

These practices of exhibition platforms in the form of panels, round tables and presented workshops results have acquired their place also within the magazine concept of exhibiting architecture, however, it most often concerns an attempt that the manifestation frame is thematically expanded and thereby the public attention diverted or open the wider social communication on the issues of the trade and not that much on the intention that already the presentation itself or exhibiting of the examples of architecture have necessarily oriented activity in respect to broader realized communications.

It is only at the level of the individual author's concepts exhibitions realized by both formal and informal groups of architects, studies or similar forms of professional associations that the significantly thoughtful conceptions or narrative presentation of the author's work can be perceived. These exhibitions do not operate with as complex medium presentation of architecture as much with the attempts of presenting a certain conceptual narrative or process of architectural thinking as a consistent strategy of thinking in architecture. Although the way of exhibiting is in the form of conventional poster type presentation of architecture or presentation in the form of working model or a series of models, it is visible the striving to clearly define discursive framework within which architecture is articulated and the presentations are not only literal images of the realized or designed architectural forms as much different typologies of presentations, from abstract presentations or texts to photographs, as elements which create a complex designative chain in an attempt to define the concepts or strategies of architectural action. The aspiration to use the modern types of communication such as video, digital animation or integration of internet or some other form of searching documentary or archived material included in the presentation, is more one type of assistance in presentation of the complexity of the exhibited narrative than it falls within the domain of the attempt to carry out the presentation in a more communicative medium manner. 
These contemporary means are often the indicators of a certain aspiration for credibility of the contemporary concept of communication with artifact rather than the media which function is to expand the ways of communication in conceptual sense through different models of interaction.

It is noticeable, however, that after 2000 the interest becomes more complex of the visual artists to act in the medium of architecture by creating specific interventions in space or ambience installations whereby certain type of public social message is thematized. From that standpoint architecture is identified as a significant urban artifact of the society with its necessary economic, productive, social and cultural constitution. The inspiration with architecture medium ensues from the insight made into its intrinsic life role both in the individuals, in special social groups or the society as whole. These medium forms of exhibiting very often abolish the boundary between strictly architectural professional action and artist's act.

This form of art exhibiting has not been developed in Serbia only and exclusively by the artists whose professional interest was logically oriented towards the production of complex visual artifacts but also towards the architects they researched in the domains of installation or ambience. Unfortunately, these researches have been reduced to a smaller number of mostly younger artists who performed such type of production usually within the multimedia artistic and architectural manifestations or program workshops which became a standard form of work and research after 2000.

The reasons of relatively modest exhibiting of the complex medium form of architecture are found in poor economic conditions of production which do not provide the continuity of work and research and not that much in non-interest of the active participants to research or express themselves in this way.

Therefore it is noticeable that in the more simple media the expression and exhibiting, such as photography, the entire groups of architects and artists are engaged in rather interesting presentations of architecture and not necessarily through the attempts of recording architectural forms but in the ways to use photography as medium of rather complex conceptual strategies with a support on creating the recognizable identity of possibly realizable architecture.

The most significant result of the changeable paradigm of exhibiting architecture in Serbia after 2000 relates to the Serbian participation in presentation of the national architecture at the Venice Biennale of Architecture. Following greater number of conventional exhibitions of the local production there came to 
the aspiration to present the Serbian architecture in the ways related to the presentations of the developed countries. Withdrawing from presentation of the local production with an awareness that its ranges are not that great so they could make a credible effect in the circumstances of global production the juries of this presentation sought to find out the mode of presentation which would move towards the attempt to present a country through promotion of its awareness of architecture rather than through the form of its realizations.

This act was also principally complementary to the exhibiting system in Venice where the majority of national representations have not dealt as much with their own production as much as with making the promotion of their contemplative and strategic researches within the field of architecture. With regards to the theme concept, these exhibitions presumed a certain form of interaction with the theme of exhibition in order to introduce the presentation concept into correspondence with the major global streams of thinking in architecture.

Hence the focus of exhibiting was placed on the level of installation, ambience, or ambience installation as media forms having the function to speak about the sense of architectural action rather than to describe its formal properties. A too small number of these realizations have not managed yet to raise the public awareness in Serbia to the level whereby more complex social and cultural functions of architecture are contemplated with such forms of presentation. A certain doze of inexperienced architects informing the authentic art visual ambience, often supplemented with more or less inadequate examples of the current local production and also the circumstance of the lack of funds for more complex media realizations has not crucially influenced the concepts of exhibiting, however, it certainly has affected the compromise solutions in realizations which necessarily decrease the credibility of presentation.

That has not diminished the meanings of their conceptual and content narratives. They have been calculated to the possibility that the local opinion of architecture be placed on the level of globally important and that in such way the awareness of the local society of architecture is represented. These realizations in a most direct way affirm the thesis how the intent of the Serbian architecture has primarily been oriented towards achieving the leading global standards even at least in the way of thinking if not in the possibilities of formal realization of such ways of thinking in architecture.

In the analysis of herein mentioned set of examples of exhibiting architecture after 2000 it is evident a significant lacking of greater and more serious presentations of so-called "paper architecture", utopian designs or various 
forms of research in architecture. It is quite interesting that just these forms of presentation are the most meaningful in the form of exhibition inside gallery or museum space. Naturally, this does not mean that there are no such examples, however, their existence is almost all unidentifiable and publicly inaccessible. A certain number of unrealized competition achievements nowadays have a significant and rather indicative public value but such values have not been strategically presented and interpreted in full.

If the history of local architecture orients us towards the acts of Micic Zenit, Nikola Dobrović, for example, and his plans, formidable activities of Bogdan Bogdanović in forming various utopias whereby he got moving the entire generations of architects like the "Mec" group, for example, as the actions which nowadays have their significant place in the local history of architecture then the fact is clear that exhibiting architecture in Serbia has not been well positioned within cultural context, and that not only there are no example of various action within architecture nowadays, but because its meaningful and conceptual strategic exhibiting is necessarily needed in order for it to initiate the social dialogue and so that itself would become historically valid independently from its objective realization.

Catalogues of the architectural event BINA published by the Association of Belgrade Architects and the Association of Serbian Architects, Belgrade;

Issues relating the Mikser Festival and in Belgrade;

Project X, Old sugar factory, Belgrade, April 1996;

Lust for life (Festival dedicated to Wilhelm Reich), Workshop 301, W.R.:301, Faculty of Architecture, Belgrade, November 16, 1997;

Historical Framework of Memories (environment for listening of the voices of the past), Project authors: Z. Erić, S. Vuković, Organization: Museum of Contemporary Art, Belgrade and Center for Visual Culture MCAB with the support of Erste Stiftung, in cooperation with INEXExpeditio, Inex Film, Belgrade, November 11, 2011. 
Basu, Paul, and Sharon Macdonald. "Experiments in Exhibition, Ethnography, Art and Science." In Exhibition Experiments, ed. Sharon Macdonald and Paul Basu. Oxford: Blackwell, 2007.

Blau, Eve. "Exhibiting Ideas." Journal of the Society of Architectural Historians 57/ 3 (September 1998): $256-366$.

Cohen, Jean-Louis. "Exhibitionist Revisionism: Exposing Architectural History." Journal of the Society of Architectural Historians 58/ 3 (September 1999): 316-325.

Dernie, David. Exhibition Design. New York: W.W. Norton \& Company, 2006.

Exhibiting Architecture: A paradox? Yale School of Architecture, http://architecture.yale.edu/ school/events/exhibiting-architecture, (visited on November 2013)

Feireiss, Kristin. "It's Not About Art." In The Art of Architecture Exhibitions, Edited by Kristin Feiress and Jean-Louis Cohen. Rotterdam: NAi Publishers, 2001.

Feireiss, Kristin, and Jean-Louis Cohen, eds. The Art of Architecture Exhibitions. Rotterdam: NAi Publishers, 2001.

Psarra, Sophia. Architecture and Narrative: The Formation of Space and Cultural Meaning. London: Routledge, 2009.

Psarra, Sophia, and Tadeusz Grajewski. "Architecture, narrative and promenade in Benson + Forsyth's Museum of Scotland." arq 4, no. 2 (2000): 123-36.

Rashid, Hani. "Installing Space." In The Art of Architecture Exhibitions, ed. Kristin Feiress and Jean-Louis Cohen. Rotterdam: Nai Publishers, 2001.

Simon Pennec, Exhibiting Architecture: A paradox?, Domus, digital edition, http://www. domusweb.it/en/op-ed/2013/10/24/exhibiting_architecture_a_paradox_html, (visited on November 2013)

Watson, Fleur. Beyond Art, The Challenge of Exhibiting Architecture http://www.dhub.org/ beyond-art-the-challenge-of-exhibiting-architecture/ (visited on November2013) 


\section{STRATEGIJE IZLAGANJA I PREZENTACIJE ARHITEKTURE KAO IZLOŽBENE FORME \\ (sa osvrtom na izlagačke prakse u Srbiji \\ nakon 2000. godine)}

\section{Milorad Mladenović}

Ovaj tekst bavi se postojećim i mogućim modalitetima i strategijama izlaganja i prezentacije savremene arhitekture i to u specifičnim izlagačkim uslovima (galerijskim ili muzejskim prostorima ili u kontekstu javnog prostora), bez namere da se pitanje prezentacije posmatra u svim njenim aspektima s obzirom na složenost i sve okolnosti širine ove teme. Težište ovog teksta postavljeno je na nivo istraživanja odnosa između realnog modela i njegove prezentacije ili na različitim načinima interpretacije projektovanog modela u kontekstu njegove moguće realizacije ili neke njegove posebne programske ili utopijske društvene funkcije. Takođe, težište teksta bazirano je na analizi medijskih praksi prezentacija ideja i koncepata u arhitekturi, kao i na mogućnostima da se arhitektura prezentuje kao profesionalna, umetnička i društvena praksa putem tih medija.

U posebnom delu ovog teksta biće predstavljena praksa izlaganja i prezentacije srpske arhitekture nakon 2000. godine kroz analizu sistema i oblika izlaganja u postojećim društvenim i kulturnim uslovima od značaja za oblast arhitekture, a na osnovu prethodno datih analiza.

KLJUČNE REČI: IZLAGANJE ARHITEKTURE, MODELI IZLAGANJA, MEDIJI IZLAGANJA, MODELI KOMUNICIRANJA, PROSTOR IZLAGANJA, IZLAGANJE ARHITEKTURE I UMETNOSTI, IZLAGAČKE PRAKSE U SRBIJI

\section{IZLOŽBENI SINDROM: ARHITEKTURA KAO EKSPONAT}

\section{Mladen Pešić}

U ovom istraživanju, izložbe se razmatraju prevashodno kao institucije, odnosno kao mesto interakcije različitih identiteta kroz izbor eksponata, njihovu prezentaciju, prostornu dispoziciju i kroz odabir i upotrebu pratećih tekstova. Ovako postavljen kontekst istraživanja pokušaće da odgovori na pitanje na koji način je moguće konstruisati istoriju izložbi - zaboravljenih, često bez dovoljno dokumentacije ili zapisa o njima. Pored toga, preispitaće se na koji način su izložbe pomogle u stvaranju i promovisanju ideje arhitekture tokom 20-og veka, preklapajući se sa smenama diskursa, širih filozofskih rasprava i tehnoloških inovacija. 